\title{
Long-term radiographic follow-up of the Nissen fundoplication in children
}

\author{
C.E. Blane ${ }^{1}$, R.H. Turnage ${ }^{2}$, K.T. Oldham ${ }^{2}$ and A.G. Coran ${ }^{2}$ \\ Departments of ${ }^{1}$ Radiology and ${ }^{2}$ Surgery, University of Michigan Hospitals, Ann Arbor, Michigan, USA
}

\begin{abstract}
This study examined 46 children 5-9 years (mean 6.7) after Nissen fundoplication surgery for gastroesophageal reflux (GER). Eleven were deceased and ten of the 35 families declined objective evaluation. The remaining 25 children $(71 \%)$ had a barium swallow examination. In 16 of the 25 patients the fundoplication was intact. In 2 patients a small portion of the fundoplication was displaced above the diaphragm. In 5 patients there was residual esophageal disease. In 3 patients (one with esophageal disease), with a hiatus hernia prior to surgery, despite immediate postoperative reduction, the barium swallow examination done for this study revealed recurrent hiatus hernia but no GER. Long-term results of the Nissen fundoplication reveal success in eliminating clinically significant gastroesophageal reflux. Those patients with esophageal disease prior to the surgery need close interval follow-up to monitor continuing problems.
\end{abstract}

Utilization of the Nissen fundoplication procedure for gastroesophageal reflux (GER) in infants and children has increased significantly over the past decade at our institution. It is now one of the most commonly performed surgical procedures. The immediate postoperative radiographic findings and techniques have been reported in the literature [1-6]. The immediate postoperative complications have been best detailed in adult series though one recent report includes children [7-11]. Concern that there are no long-term evaluations of this now common procedure in children, many of whom have other serious medical illnesses, raised the question as to whether the additional surgery in this population with high morbidity and mortality was warranted. This study was designed to objectively evaluate the long-term success of the operation in children who were more than 5 years postoperative since their Nissen fundoplication.

\section{Patients and methods}

Between 1974 and 1982 fifty-six children underwent the Nissen fundoplication operation at this institution. The procedure involved a $360^{\circ}$ fundal wrap fixed to the esophagus and esophageal hiatus. Ten of these patients have been lost to follow-up, the remaining 46 patients comprise the study group. Over half of the $46(57 \%)$ had significant preoperative neurologic impairment (primarily cerebral palsy) and $80 \%$ had at least one other serious medical illness including diagnoses such as Down's syndrome, Noonan's syndrome, juvenile rheumatoid arthritis and congenital heart disease. Age at operation ranged from 1 month to 18 years (mean $=4$ years). Of the 46 children, 11 were deceased at the time of this study, though no death was directly related to the Nissen fundoplication ( 8 children died as a direct result of their severe neurologic impairment, 3 children died as a result of their severe congenital heart disease, 1 child died of complications from a persistent tracheoesophageal fistula, and 1 child died with peritonitis complicating small bowel obstruction 9 months following Nissen fundoplication). Ten patients and their families underwent subjective evaluation in terms of a history and physical examination but declined further objective evaluation. The families were satisfied with the results of the surgery and did not want to take the time to come to the hospital for further investigation. The remaining 25 children had a barium swallow examination after signing an informed consent approved by the Human Use Committee at the University. The findings in this latter group constitute the results in this report. 

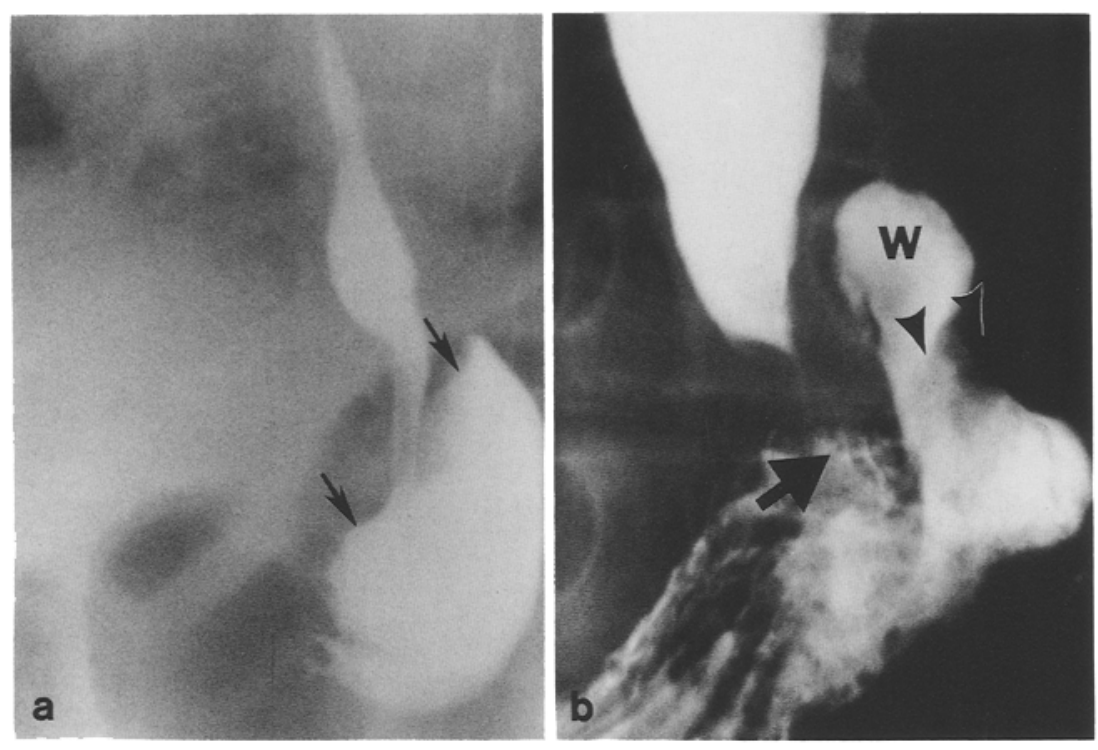

Fig.1. a Normal postoperative appearance of defect from wrap (arrows). b The gastroesophageal junction (arrow) is separate from the portion of the wrap $(W)$ above the diaphragm (arrowheads), in this 17-yearold patient 6 years postoperatively

\section{Results}

We completed 25 barium swallow examinations, 18 of which were normal postoperative studies with satisfactory opening at the gastroesophageal junction (Fig. 1a). There was no significant GER demonstrated in this group [12]. In long-term follow-up the soft tissue defect from the wrap was present in these children but not always easily identified and positioning was necessary to visualize the impression of the fundoplication. Since 6 of the patients were severely mentally impaired, 5 of them with gastrostomy tubes for feeding, turning them to optimally visualize the soft-tissue mass defect from the intact wrap was difficult. There were five other patients in this group with mild mental retardation, including 2 with Down's syndrome and 1 with $\mathrm{G}$ syndrome. The other 7 children included 1 patient with systemic lupus erythematosus and 1 patient with esophageal atresia repair. The barium studies of two patients revealed a superiorly placed corner of the gastric fundus portion of the fundoplication above the diaphragm (Fig.1b). There was no significant reflux demonstrated whether the position of the wrap was above or below the diaphragm [13].

Five patients had an intact fundoplication without GER, but had other evidence of residual or continuing esophageal disease. Of these, three children had presented initially with GER and esophageal ulcers, one patient with Williams' syndrome, one boy with juvenile rheumatoid arthritis and one child with mental retardation. Narrowing at the site of previous ulcer disease persisted and/or recurred by the time of this follow-up study. The patients had undergone esophageal dilatation. The other two patients had presented with severe esophageal dysmotility following repair of esophageal atresia which had not changed at the time of the study. One child had been admitted for dilatation of the fundoplication. They were 2 of the 3 patients in this study with primary esophageal atresia repair. All 3 patients with primary esophageal atresia repair had at least one admission to our institution for food or foreign body lodged above the Nissen fundoplication wrap that had to be removed endoscopically.

There were 3 patients who initially presented with hiatus hernia in addition to gastroesophageal reflux (Fig.2a). Two had no other medical problems; however, one child with mental retardation also had esophageal disease. The radiographic follow-up in the immediate postoperative period showed reduction of the hernia (Fig. 2b). However, at the time of these studies the hernia had recurred in all of these children (Fig.2c). Gastroesophageal reflux was not demonstrated on these follow-up barium studies but contrast did wash back and forth between the portions of the stomach that were above and below the diaphragm.

Clinical histories from all families except those with preoperative esophageal disease indicated a marked reduction or complete absence of hospital admissions for pneumonia, vomiting and poor feeding, which had been a major problem prior to the Nissen fundoplication. This data could not be quantified or objectively documented since the patients came from many small communities and had been admitted to many different institutions which they had difficulty enumerating prior to the surgery. 

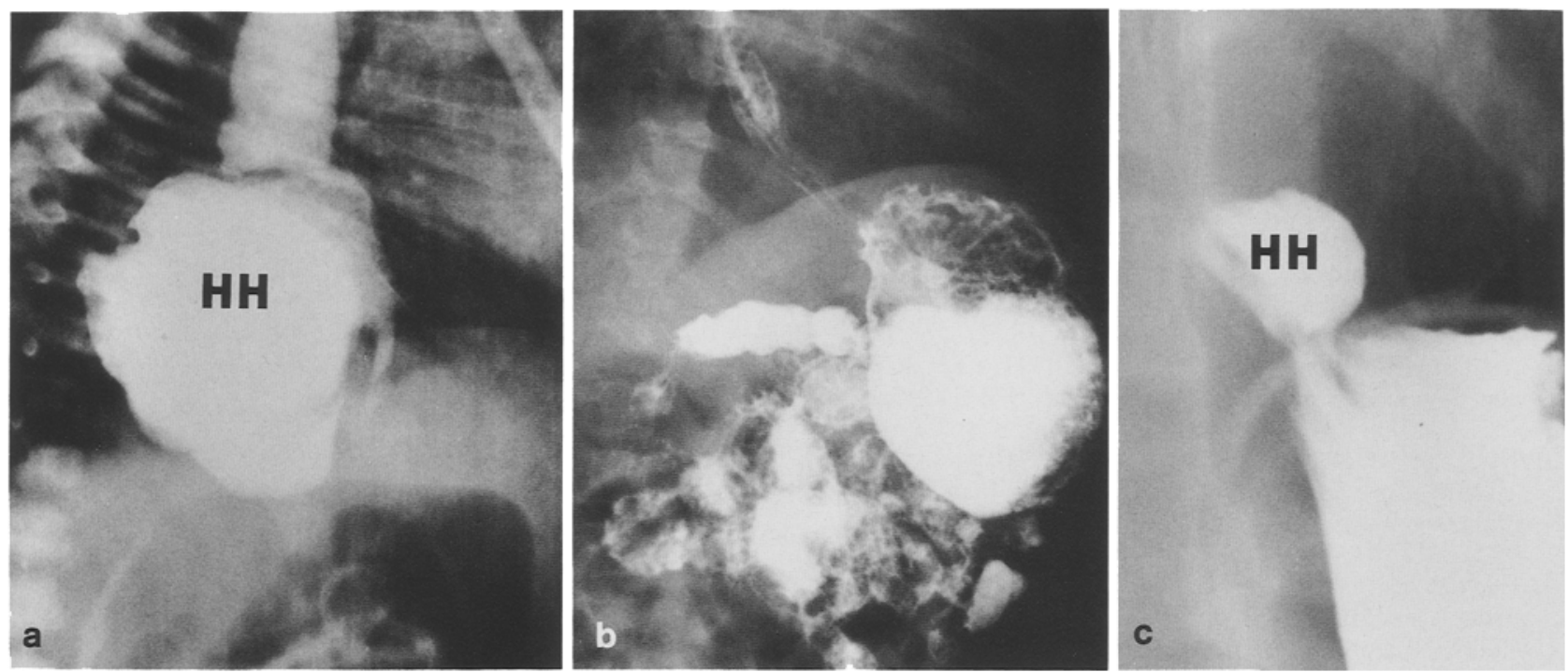

Fig. 2. a This 2-week-old girl was referred with hiatus hernia $(H H)$ and GER. b The barium study 2 months postoperatively revealed reduction of the $\mathrm{HH}$ and no GER. c Follow-up study 9 years postoperatively demonstrates recurrence of the hiatus hernia (HH) but not the GER

\section{Discussion}

In the last decade there has been a significant increase in the number of infants and children treated surgically for gastroesophageal reflux. Some of this increased demand for surgical correction may be related to the longer survival and different needs of home care of many of these children with severe medical problems compared to the previous institutional care many received $[11,14]$. Over half of this surgical population is neurologically impaired, often very severely, and the majority of the patients have a severe handicap [11, 14]. Eleven of the 46 children (almost 25\%) at the time of follow-up were deceased. However, only one death, that child with a small bowel obstruction, could only indirectly be related to the Nissen fundoplication surgery.

Minor findings included recurrence of the hiatus hernia but without documented reflux in the children with preoperative hiatus hernia. In addition, the position of a portion of the wrap of a Nissen fundoplication above the diaphragm in an axial hiatus hernia did not seem to present any complications. It was incidentally found in two of the $25(8 \%)$ cases.

This study indicates that the majority of patients, often with severe underlying illness, do well.
The patients that require careful follow-up are those with esophageal disease prior to the surgery. Esophageal disease in this group of patients included those with severe dysmotility following esophageal atresia repair and ulcerative changes. Those patients with severe dysmotility of the esophagus continued to have the problems associated with the dysmotility. There was poor growth and problems with food and foreign objects lodging above the gastroesophageal junction. Balancing the morbidity associated with reflux esophagitis against the problems of a dysmotile esophagus, and against a tight gastroesophageal junction following Nissen fundoplication, can be difficult. Preoperative ulcerative disease of the esophagus in these children, in spite of documented postoperative resolution of the gastroesophageal reflux, resulted in long-term fibrosis, scarring, and recurrent stricturing at the original site of ulceration.

The long-term results of this increasingly popular operation in infants and children are good in this patient population with an extremely high association of serious underlying medical problems. However, those patients with esophageal disease prior to the corrective surgery are at risk for persistence, recurrence, or complications of the same and should be followed carefully.

\section{References}

1. van Kuyk PJ (1976) Diagnostic radiology in fundoplication according to Nissen. Radiol Clin 45:115

2. Cohen WN (1968) The fundoplication repair of sliding esophageal hiatus hernia: its roentgenographic appearance. AJR 104: 626 
3. Feigin DS, James AE Jr, Stitik FP, Donner MW, Skinner DB (1974) The radiological appearance of hiatal hernia repairs. Radiology 110: 71

4. Skucas J, Mangla JC, Adams JT, Cutcliff W (1976) An evaluation of the Nissen fundoplication. Radiology 118: 539

5. Agha FP, Trenkner SW, Orringer MB, Vinh PN (1985) The combined Collis gastroplasty Nissen fundoplication: surgical procedure and radiographic evaluation. AJR 145: 729

6. St Cyr JA, Ferrara TB, Thompson TR, Johnson DE, Foker JE (1986) Nissen fundoplication for gastroesophageal reflux in infants. $J$ Thorac Cardiovasc Surg 92:661

7. Carcassonne M, Bensoussan A, Aubert J (1973) The management of gastroesophageal reflux in infants. $\mathbf{J}$ Pediatr Surg 8: 575

8. Henderson RD, Ryder D, Marryatt G (1987) Extended esophageal myotomy and short total fundoplication hernia repair in diffuse esophageal spasm: five-year review in 34 patients. Ann Thorac Surg 43:25

9. Bettex M, Kuffer F (1969) Long-term results of fundoplication in hiatus hernia and cardio-esophageal chalasia in infants and children. Report of 112 consecutive cases. J Pediatr Surg 4:526

10. Thoeni RF, Moss AA (1979) The radiographic appearance of complications following Nissen fundoplication. Radiology 131: 17

11. Dedinsky GK, Vane DW, Black CT, Turner MK, West KW, Grosfeld JL (1987) Complications and reoperation after Nissen fundoplication in childhood. Am J Surg 153: 177
12. McCauley RGK, Darling DB, Leonidas JC, Schwartz AM (1978) Gastroesophageal reflux in infants and children: a useful classification and reliable physiologic technique for its demonstration. AJR 130: 47

13. Blane CE, Klein MD, Drongowski RA, Sarahan TM, Wesley JR, Coran AG (1986) Gastroesophageal reflux in children: is there a place for the upper gastrointestinal study? Gastrointest Radiol 11: 346

14. Wesley JR, Coran AG, Sarahan TM, Klein MD, White SJ (1981) The need for evaluation of gastroesophageal reflux in brain-damaged children referred for feeding gastrostomy. I Pediatr Surg 16: 866

Received: 7 November 1988; accepted: 2 March 1989

C. Blane, M.D.

Section of Pediatric Radiology

Department of Radiology

University of Michigan Hospitals

Mott C3123/0252

1500 E. Medical Center Drive

Ann Arbor, MI 48109-0252

USA

Literature in pediatric radiology (continued from p.519)

Journal of Computer Assisted Tomography (New York)

Xenon-CT cerebral blood flow evaluation of cerebral ischemia in children and young adults. Stringer, W. A. et al. (Hasso, A. N., Dept. of Rad. Sciences, Section of Neurorad., Univ. Med. Center, 11234 Anderson Street, Loma Linda, CA 92354, USA) 13, 386 (1989)

Computed tomography in abdominal Castleman's disease. Ferreirós, $\mathbf{J}$. et al. (Dept. of Rad., Hospt Univ, de San Carlos, PI/Cristo Rey, $s / n$, 28040-Madrid, Spain) 13, 433 (1989)

Neonatal dural venous sinus thrombosis associated with central venous catheterization: CT and MR studies. Hurst, R.W. et al. (Dept. of Rad., Box 170, Univ. Med. Center, Charlottesville, VA 22908, USA) 13, 504 (1989)

Thrombus calcification of renal vein in neonate: ultrasound and CT diagnosis. Starinsky, R. et al. (Assaf Harofeh Med. Center, Zerifin 70300, Israel) 13,545 (1989)

\section{Journal of Neurosurgery (Battimore)}

Magnetic resonance imaging in myelocystoceles. Peacock, W. J., Murovic, J.A. (Section of Ped. Neurosurg., Div. of Neurosurg., Univ. School of Med., 10833 Le Conte Ave., 74-137 Center for the Health Sciences, Los Angeles, CA 90024, USA) 70, 807 (1989)

Journal of Nuclear Medicine (New York)

Scintigraphic features of choledochal cyst. Camponovo, E. et al. (Buck, J. L., Editorial Office, Armed Forces Inst. of Path., Room 4018, Washington, DC 20306-6000, USA) 30, 622 (1989)

Detection of pulmonary aspiration in children by radionuclide ${ }_{n}$ salivagram“. Heyman, S., Respondek, M. (Div. of Nucl. Med., The Children's Hosp., 34th St. and Civic Center Blvd., Philadelphia, PA 19104, USA) 30, 697 (1989)

\section{Journal of Pediatrics (St. Louis)}

Extracardiac chest ultrasonography in infants and children: radiographic and clinical implications. Glasier, C. M. et al. (Dept. of Rad., Children's Hosp., 800 Marshall St., Little Rock, AR 72202, USA) 114, 540 (1989)

Ovarian ultrasound appearances in Turner syndrome. Massarano, A. A. et al. (Brook, C. G. D., The Middlesex Hosp., Mortimer St., London WIN $8 \mathrm{AA}$, England) 114, 568 (1989)
Journal of Pediatric Surgery (New York)

Radiologic evaluation of surgical resectability in abdominal neuroblastoma. Saeki, M. et al. (Dept. of Surg., National Children's Hosp., 3-35-31, Taishido, Setagaya-ku, Tokyo 154, Japan) 24, 378 (1989)

Giant cystic hygroma of the posterior mediastinum. Curley, S.A. et al. (Kosloske, A. M., Dept. of Surg., Room 233, Univ. Hosp., 2211 Lomas Blvd. NE, Albuquerque, NM 87106, USA) 24, 398 (1989)

Giant spontaneous duodenal hematoma in hemophilia A. Nogués, A. et al. (Tovar, J. A., Parque Nuevo Igueldo, 6, 20009, San Sebastián, Spain) 24, 406 (1989)

Intravenous digital subtraction angiography: its use in evaluating vascular injuries in children. Parker, P. M. et al. (Weintraub, W. H., Dept. of Surgery, St Christopher's Hosp. for Children, 2600 N Lawrence St, Philadelphia, PA 19133, USA) 24, 423 (1989)

Pulmonary septic emboli mimicking metastatic rhabdomyosarcoma. Stine, K. C. et al. (Dept. of Ped., Box 2916, Duke Univ. Med. Center, Durham, NC 27710, USA) 24, 491 (1989)

Superficial femoral vein transposition in Klippel-Trenaunay syndrome. Taheri, S. A. et al. (1275 Delaware Ave., Buffalo, NY 14209, USA) 24, $494(1989)$

Journal of Urology (Baltimore)

Lower pole ureteropelvic junction obstruction and incomplete renal duplication. Joseph, D. B. et al. (The Children's Hosp., 1600 Seventh Ave., S., Birmingham, AL 35233, USA) 141, 896 (1989)

Accuracy of bladder volume determinations in children using a suprapubic ultrasonic bi-planar technique. Williot, P. et al. (Hosp. for Sick Children, Toronto, Ontario, Canada) 141, 900 (1989)

Pelvic neuroblastoma. Knoedler, C. J. et al. (Section of Ped. Urol., Dept. of Urol., Clinic Foundation, Cleveland, OH) 141, 905 (1989)

Percutaneous sclerotherapy of idiopathic varicocele in childhood: a preliminary report. Thon, W. F. et al. (Dept. of Urol., Academic Hosp. of the Univ., D-7900 Ulm, FRG) 141, 913 (1989)

Residual urine in children with acute cystitis and in healthy children: assessment by sonography. Lidefelt, K.-J. et al. (Dept of Ped. and Ped. Rad., Karolinska Inst, Sachs' Children's Hosp., Stockholm, Sweden) $141,916(1989)$ 